\title{
Effects of Various Injection Holes with/without Opening Angles of Film Cooling on Blades of Gas Turbine: A CFD Approach
}

\author{
Ebrahim Hosseini \\ Department of Mechanical Engineering, Dezful Branch, Islamic Azad University, Dezful, Iran
}

(Corresponding author's e-mail: ebrahim.2019.hosseini@gmail.com)

Received: 9 August 2020, Revised: 4 May 2021, Accepted: 9 May 2021

\begin{abstract}
The combustor exit temperature is steadily rising to improve the overall efficiency of the gas turbine. As a result, film cooling, the most important and necessary cooling technology, must be developed further to satisfy this demanding requirement. The film cooling performance on the NACA 0012 gas turbine blade is numerically evaluated in this research using 6 different injection holes with and without opening angles. The Computational Fluid Dynamics (CFD) software Ansys Fluent v16 is used to conduct 2-dimensional Reynolds-Averaged Navier-Stokes (RANS) flow and heat transfer analyses. The flow is assumed to be steady, turbulent, and incompressible. To obtain solutions, the incompressible RANS equations are solved using the finite-volume technique. The simulation results indicate that the SST k- $\omega$ turbulence model is appropriate for simulating flow characteristics and evaluating film cooling efficiency over the blade. Furthermore, the opening angle has a beneficial impact on the upper blade surface's cooling performance. The injection hole with an opening angle of $15^{\circ}$ and a height of D (injection hole diameter) achieves the maximum value of cooling efficiency. The coolant injected from the hole provides greater cooling coverage for the entire blade in this configuration, increasing cooling effectiveness.
\end{abstract}

Keywords: Computational Fluid Dynamics (CFD), Cooling efficiency, Film cooling, Injection holes, NACA 0012

\section{Introduction}

High-efficiency gas turbine engines must use effective cooling schemes to maintain metal parts under allowable working temperature ranges due to unusually high turbine inlet temperatures. Film cooling is one of the most effective methods of cooling turbine blades [1]. The turbine inlet temperature rises far beyond the turbine blade melting point to improve the thermal performance of aero engines. As a result, turbine blade cooling is needed to reduce heat load and ensure the stable operation of turbine blades. It is commonly recognized that discrete hole film cooling is useful for shielding gas turbine blades from hot gas [2]. The effect of film cooling on the aerodynamic efficiency of turbine blades is becoming increasingly critical as the operating temperature of gas turbines is increased to improve performance [3]. CFD has now found its place among experimental and analytical methods for analyzing fluid flow, heat transfer [4-10], and diverse problems [11-15], and the use of this method for engineering analysis has become more common [16-18].

Several computational and experimental investigations have been done in the past to investigate the effect of film cooling on gas turbine efficiency [19,20]. CFD estimates of film cooling efficiency for gas turbine blades are now an essential part of the turbine cooling design process. Jackson et al. [21] studied a symmetric airfoil in a non-turning transonic test section. On the suction side, a single row of holes was mounted $49 \%$ of the chord length from the leading edge. Conical diffused holes and circular cylindrical holes were also investigated. Mamaev et al. [22] obtained their results from a vane block with film and convective cooling systems. At the leading edge, suction side, pressure side, and trailing edge, coolant air was released. They realized that coolant ejection increased profile losses, which increased even as the coolant mass flow rate was increased. Lanzillotta et al. [3] investigated the effect of blowing ratio on symmetric airfoil aerodynamic losses. The coolant air was pumped at ambient temperature, and the blowing ratio was adjusted between 0 and 1.91. They came to the conclusion that at low blowing ratios, the separation point changes upstream, while at high blowing ratios, the coolant energizes the flow and 
delays separation. Colban et al. [23] investigated the adiabatic film-cooling effectiveness of cylindrical and fan-shaped holes on a turbine vane endwall surface experimentally. Using fan-shaped holes instead of cylindrical holes resulted in a $75 \%$ improvement in film effectiveness based on area averages. Cao et al. [24] investigated the impact of hole geometry and blowing ratio on film cooling efficiency and flow structure using 4 types of film holes (cylindrical hole, fan-shaped hole, anti-vortex hole, and sister hole). The findings show that the sister hole has the highest cooling performance with a blowing ratio ranging from 0.3 to 1.5. Han et al. [25] conducted experiments to determine the effects of hole pitch and blowing ratio on the leading edge area film cooling efficiency of a turbine blade. They showed that the hole pitch and the blowing ratio all play important roles in determining the effectiveness of the film cooling. Zhou et al. [26] used a computational approach to investigate the flow and heat transfer properties of the sister holes cooling method. They concluded that the best film cooling efficiency of sister hole cooling cases was obtained with the smallest diameter ratio.

Despite the previous studies, this study attempts to numerically analyze the film cooling mechanism on the NACA 0012 gas turbine blade. Six different injection holes with and without opening angles are considered separately for this purpose. Six separate film cooling cases are investigated to find the best injection hole with the best geometry for the film cooling operation. Several numerical simulations using the CFD method are performed to provide a detailed film cooling performance of the new cooling hole shapes with opening angles.

\section{Governing equations}

The most widely used numerical approach to simulating fluid flow behavior is CFD [27-30]. In this research, the steady-state incompressible RANS equations are solved using Ansys Fluent v16, a commercial CFD code. To obtain solutions, the RANS equations are solved using the finite-volume method [31-33]. The equations for continuity, velocity, and energy have been solved. The SST k- $\omega$ turbulence model has simulated the turbulent flow, which is more reliable for the flow under consideration [34,35]. The SST k- $\omega$ turbulence model is written as follows [36]:

$$
\begin{aligned}
& \frac{\partial}{\partial t}(\rho k)+\frac{\partial}{\partial x_{i}}\left(\rho k u_{i}\right)=\frac{\partial}{\partial x_{j}}\left[\Gamma_{k} \frac{\partial k}{\partial x_{j}}\right]+G_{k}-Y_{k} \\
& \frac{\partial}{\partial t}(\rho \omega)+\frac{\partial}{\partial x_{i}}\left(\rho \omega u_{i}\right)=\frac{\partial}{\partial x_{j}}\left[\Gamma_{\omega} \frac{\partial \omega}{\partial x_{j}}\right]+G_{\omega}-Y_{\omega}+D_{\omega}
\end{aligned}
$$

where $\Gamma_{k}$ and $\Gamma_{\omega}$ are the effective diffusivity of $k$ and $\omega$, respectively. $G_{k}$ and $G_{\omega}$ are the generations of $k$ and $\omega$ due to mean velocity gradients, respectively. $Y_{k}$ and $Y_{\omega}$ indicate the dissipation of $k$ and $\omega$, respectively. $D_{\omega}$ corresponds to the cross-diffusion term of $\omega$.

Both the working fluid and the cooling fluid are referred to as air. The ratio of cold and hot air densities is assumed to be equal due to the low-temperature difference $\left(20^{\circ} \mathrm{C}\right)$ between the main flow and injection flow. As a result, the blowing ratio is expressed as the ratio of injection velocity to free stream velocity $[19,37]$ :

$$
B R=\frac{\rho_{c} V_{c}}{\rho_{\infty} V_{\infty}}=\frac{V_{c}}{V_{\infty}}
$$

where $\mathrm{Vc}$ denotes the injection velocity, $\mathrm{V}$ the free stream velocity, and represents the density The inlet flow velocity in the $\mathrm{x}$-direction is $70 \mathrm{~m} / \mathrm{s}$, and $\mathrm{T}=300 \mathrm{k}$. By assuming a blowing ratio of 1 , the velocity of the injection coolant air is assumed to be $70 \mathrm{~m} / \mathrm{s}$ at $\mathrm{Tc}=280 \mathrm{k}$. The outlet pressure is 101325 $\mathrm{Pa}$, which is the same as the air pressure. The upwind second-order approach is used to discretize equations. The SIMPLE algorithm is also used in pressure-velocity coupling. For both calculations, the convergence conditions are thought to be less than $10^{-5}$. Details of numerical settings are presented in Table 1. Many of the walls' boundary layer regions are refined to guarantee the $\mathrm{y}^{+}$values are less than 1. 
Table 1 Numerical settings.

\begin{tabular}{cc}
\hline Model conditions & Model settings \\
\hline Flow & Steady-state \\
Turbulence & SST k- $\omega$ \\
Solution method & Pressure-velocity coupling: SIMPLE \\
& Spatial discretization: \\
& Pressure: Second-order upwind \\
& Momentum: Second-order upwind \\
& Turbulent kinetic energy: Second-order upwind \\
Specific dissipation rate: Second-order upwind
\end{tabular}

The adiabatic film cooling efficiency $\left({ }^{\eta}\right)$ is expressed as [26]:

$\eta=\frac{T_{m}-T_{a w}}{T_{m}-T_{c}}$

where $T_{m}$ denotes the mainstream temperature, $T_{a w}$ is the adiabatic wall temperature, and $T_{c}$ is the coolant temperature.

\section{Materials and methods}

The 2-dimensional computational domain for the current analysis is depicted in Figure 1. The chord length of the NACA 0012 airfoil is $1000 \mathrm{~mm}$, and the injection hole diameter is $20 \mathrm{~mm}$, which is denoted by $\mathrm{D}$. The computational domain has been expanded from 5 chords upstream to 15 chords downstream, and the upper and lower boundaries have been extended 5 chords from the airfoil. The no-slip wall condition is enabled on the airfoil surface. At the inlet, upper and lower boundaries, the velocity inlet boundary condition is used, while the pressure outlet boundary condition is used at the outlet.

Figure 2 depicts the implementation of a C-type structured grid for the computational domain. For the injection holes with opening angles, 2 injection angles of $15^{\circ}$ and $20^{\circ}$ are used. Table 2 shows more details regarding injection holes. The schematic illustrations of 6 different cases of film cooling holes are provided in Figure 3.

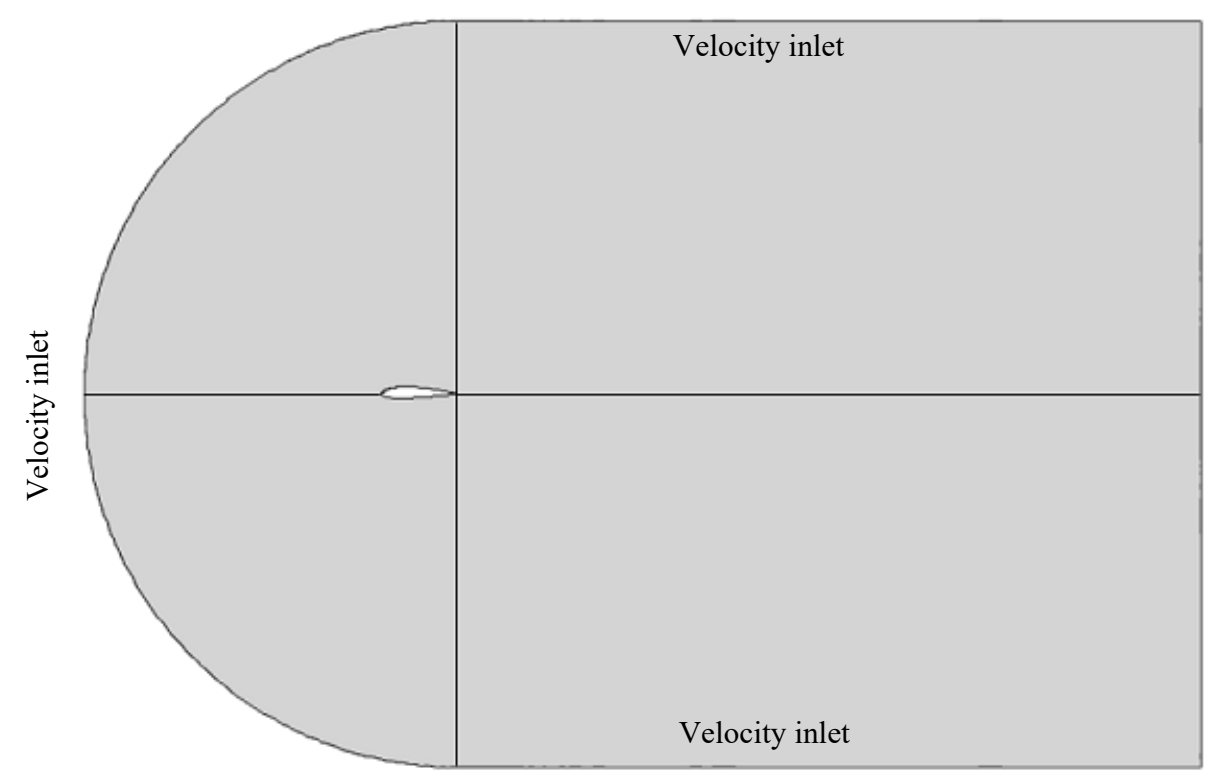

Figure 1 Computational domain. 


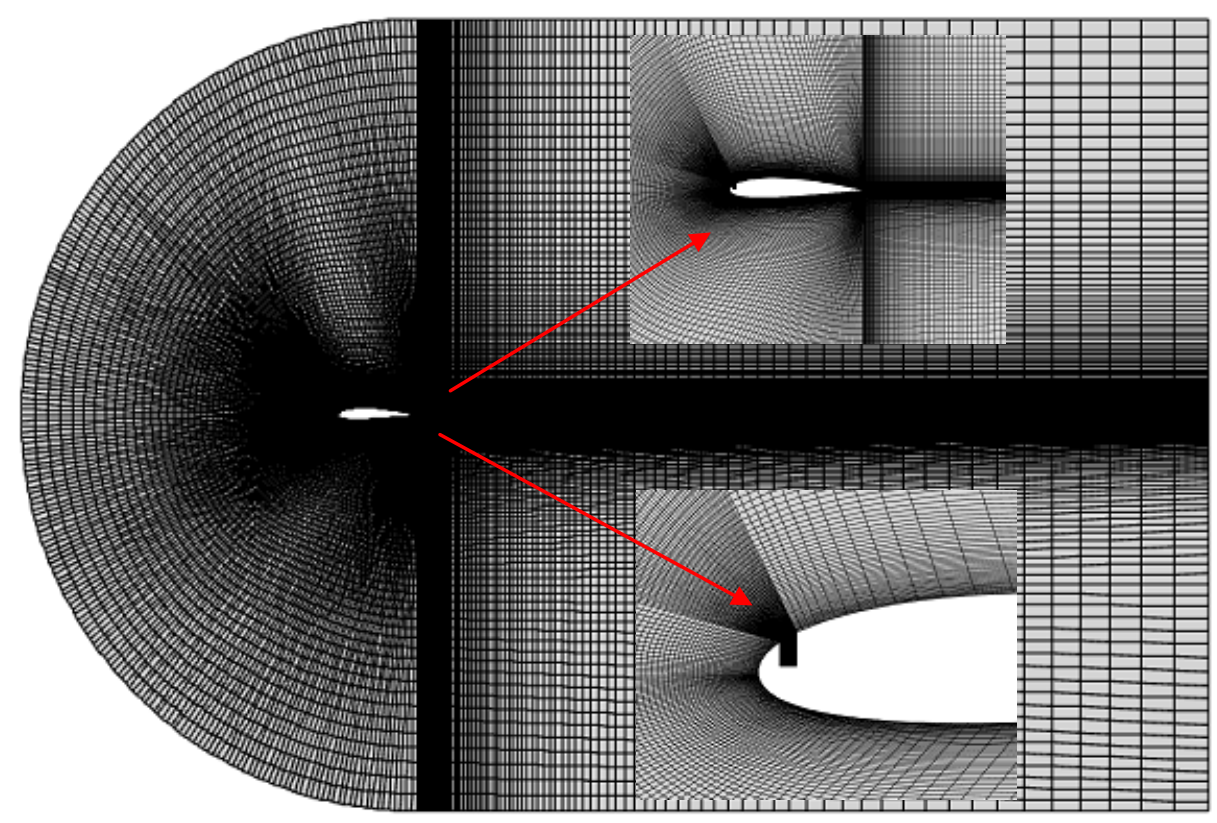

Figure 2 The boundary conditions and the entire and closer views of the grid.

Table 2 Different configurations of injection holes.

\begin{tabular}{cccc}
\hline Configurations & Width & Height & Angle $\left({ }^{\circ}\right)$ \\
\hline$\# 1$ & D & D & 0 \\
$\# 2$ & D & D & 15 \\
$\# 3$ & D & D & 20 \\
$\# 4$ & D & DD & 0 \\
$\# 5$ & D & D & 15 \\
$\# 6$ & D & 2D & 20 \\
\hline
\end{tabular}



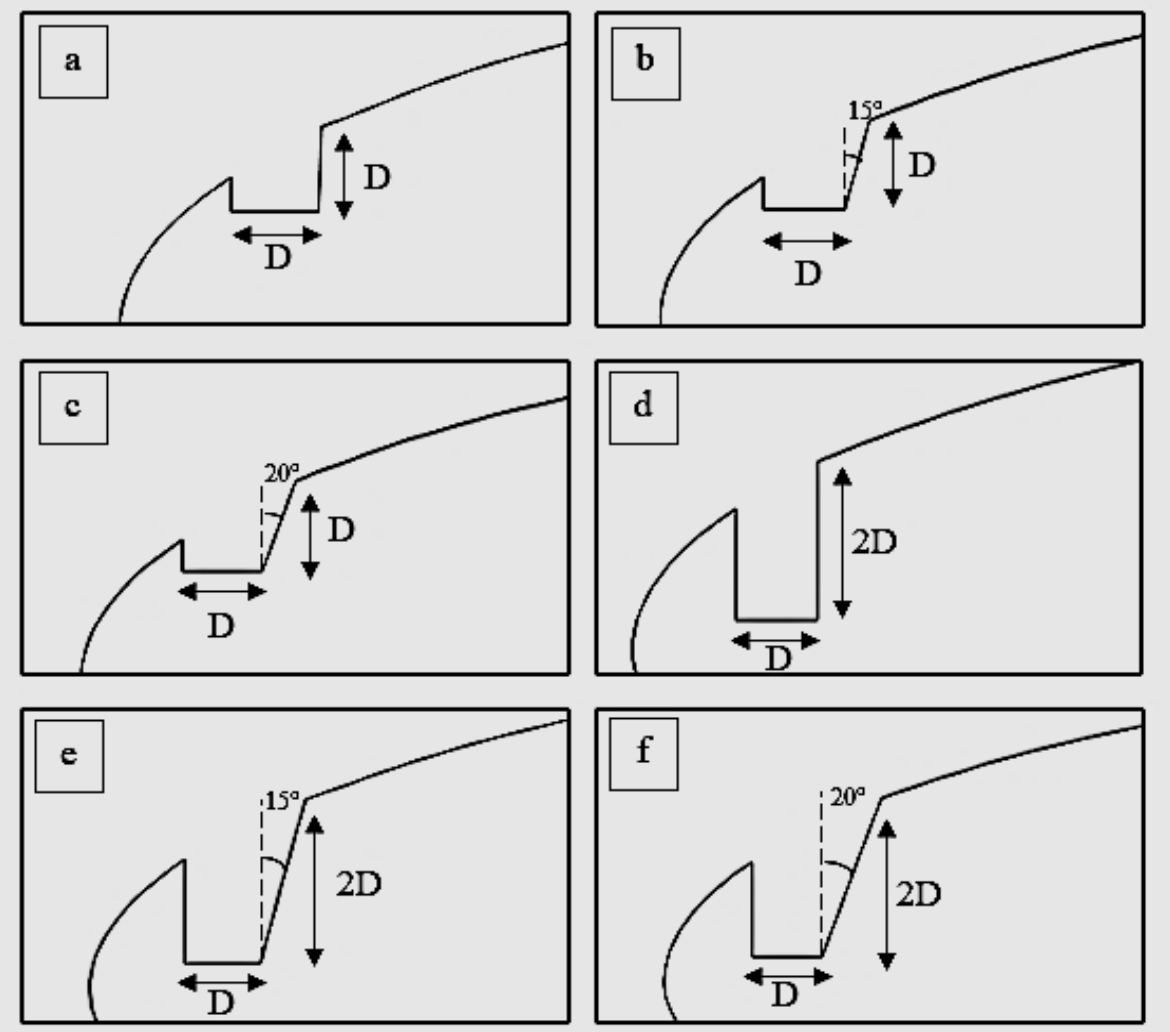

Figure 3 Schematic views of injection holes; Configuration \#1 (a), Configuration \#2 (b), Configuration \#3 (c), Configuration \#4 (d), Configuration \#5 (e) and Configuration \#6 (f).

\section{Grid independence study and validation}

Table 3 presents the grid specifications and $\mathrm{y}^{+}$distribution at $\alpha=10^{\circ}$. The value of $\mathrm{y}^{+}$is held less than 1 by taking into account the size of the closest node from the airfoil surface, which is $110(\mathrm{~m})$ [38]. The pressure coefficient $\left(C_{p}\right)$ on the asymmetric turbine blade with a cylindrical injection hole with $D$ distance is calculated using a grid independence study. To investigate grid independence, 4 separate grids with cell numbers of 35144, 45980, 52200, and 65347 are created (Figure 4). The outcomes of the smallest grid and the grid of 52200 cells vary just slightly. The grid size chosen to have a gridindependent result of reasonable reliability is 52200 nodes.

The numerical result of the pressure coefficient is compared with the experimental data of Gregory and O'reilly [39] for the NACA 0012 airfoil at a Reynolds number of $5 \times 10^{5}$ and $\alpha=18^{\circ}$ in Figure 5. The numerical validation has been done with several turbulence models: k- $\varepsilon$, RNG k- $\varepsilon$, and SST k- $\omega$. Generally, the SST k- $\omega$ turbulence model shows better agreement with the experimental results. Hence, it can be concluded that the numerical solving procedure and turbulent model have acceptable accuracy.

Table $3 \mathrm{y}^{+}$Distribution at $\alpha=10^{\circ}$ and details of the grid cells.

\begin{tabular}{|c|c|c|c|c|c|c|}
\hline Grid & $\begin{array}{c}\text { Number } \\
\text { of cells }\end{array}$ & $\begin{array}{l}\text { Growth } \\
\text { factor }\end{array}$ & $\begin{array}{l}\text { Height of the } \\
1^{\text {st }} \text { cell }(\mathrm{m})\end{array}$ & $\begin{array}{l}\text { Maximum } \\
\text { value of } y^{+}\end{array}$ & $\begin{array}{l}\text { Minimum } \\
\text { value of } y^{+}\end{array}$ & $\begin{array}{c}\text { Average } \\
\text { value of } y^{+}\end{array}$ \\
\hline 1 & 18000 & 1.1 & $2 \times 10^{-3}$ & 14.13 & 3.42 & 8.14 \\
\hline 2 & 32000 & 1.1 & $1 \times 10^{-4}$ & 6.14 & 0.83 & 2.91 \\
\hline 3 & 46000 & 1.1 & $1 \times 10^{-5}$ & 0.65 & 0.01 & 0.24 \\
\hline 4 & 65000 & 1.1 & $3 \times 10^{-6}$ & 0.61 & 0.01 & 0.22 \\
\hline
\end{tabular}




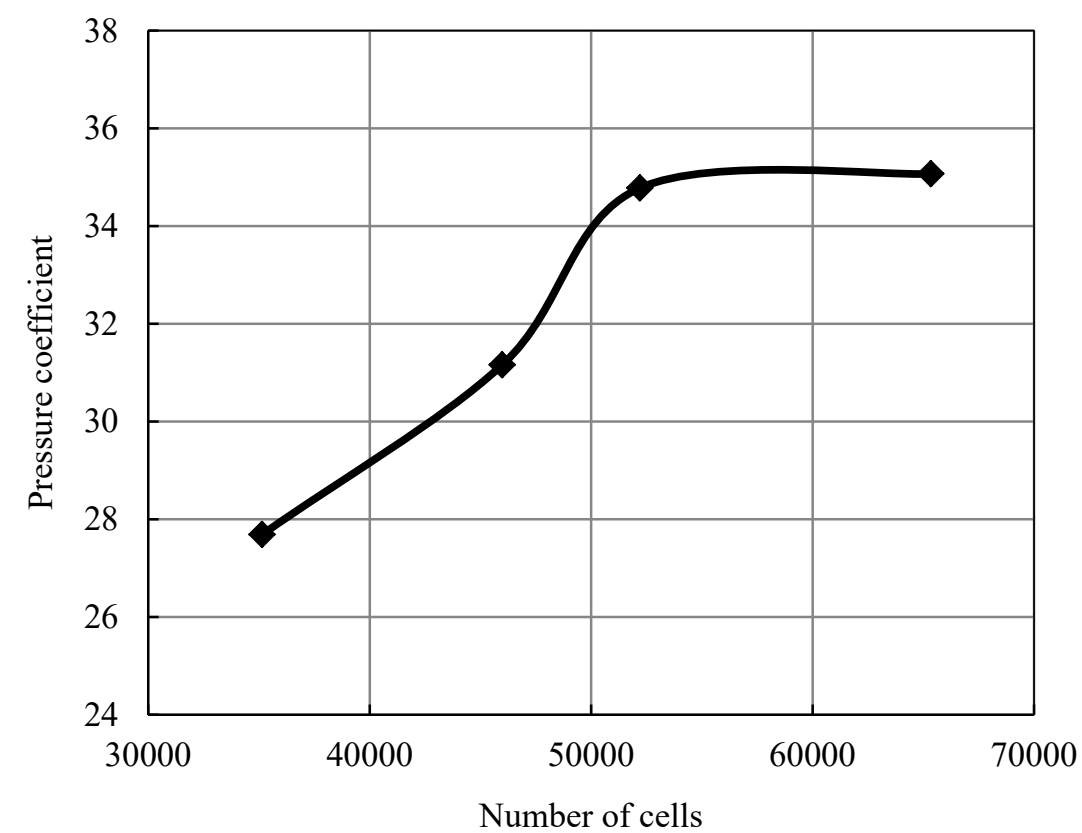

Figure 4 Grid independence study.

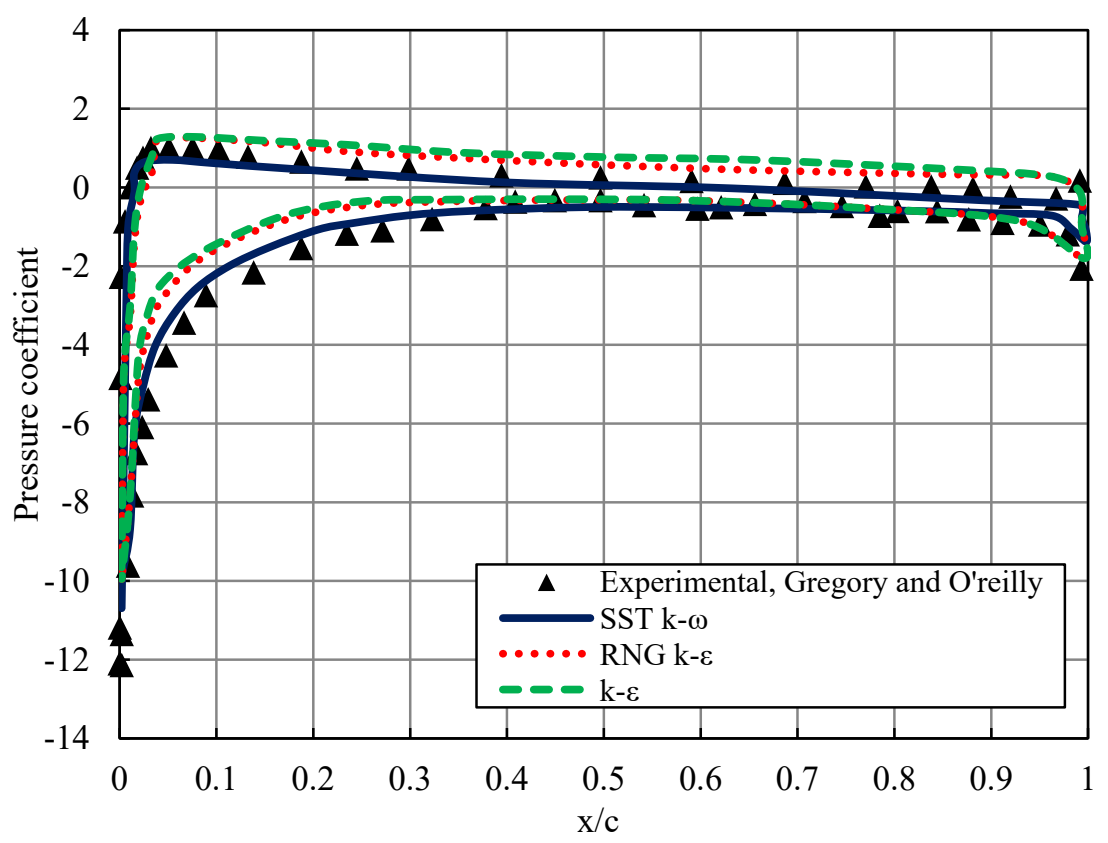

Figure 5 Comparison between the pressure coefficient $\left(\mathrm{C}_{\mathrm{p}}\right)$ with the experimental results of Gregory and O'reilly [32] at $\mathrm{Re}=5 \times 10^{5}$.

\section{Results and discussion}

Figure 6 depicts the temperature distribution (k) around the blade in both situations. Six different cases for the film cooling process are compared in this table. In both cases, the high cooling effectiveness regions can be located just downstream of the film hole exit.

As can be shown, the coolant spread is much greater for the injection hole with a $15^{\circ}$ opening angle (configuration \#2) than for the other situations. On the upper side of the blade, the coolant distribution is 
very uniform. This demonstrated that the cooling hole is sufficiently resistant to the effects of main flow acceleration and adverse pressure gradients caused by the surface's concave curvature at the trailing edge. The use of an injection hole with a $15^{\circ}$ opening angle reduces the recirculation region after the injection hole.

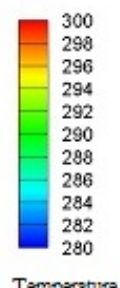

$[\mathrm{k}]$
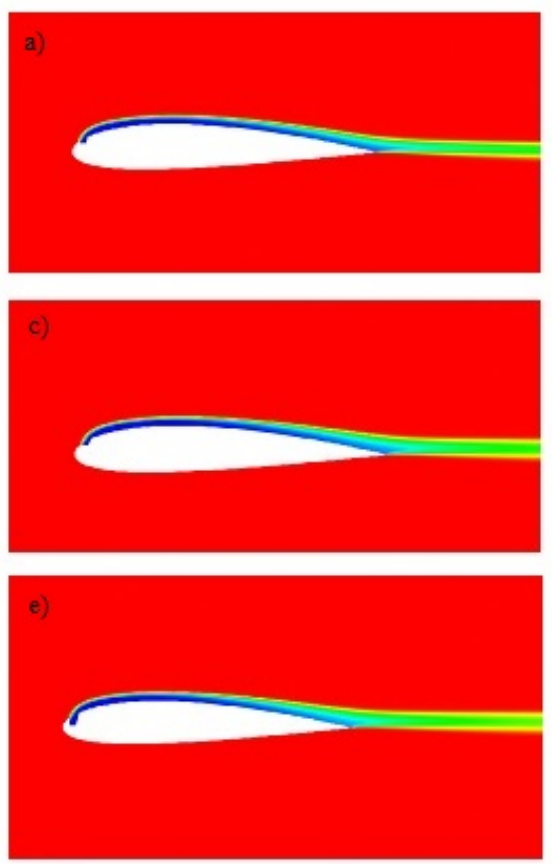
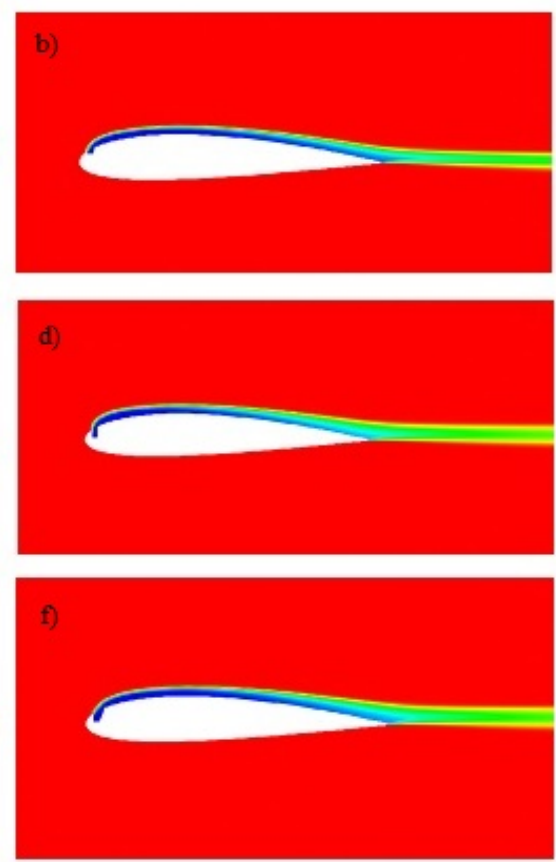

Figure 6 Temperature distribution $(k)$ over the blade; Configuration \#1 (a), Configuration \#2 (b), Configuration \#3 (c), Configuration \#4 (d), Configuration \#5 (e) and Configuration \#6 (f).

Figure 7 illustrates the velocity contours around the blade for various cases. Cooling air has a similar impact on the velocity flow field. The injection hole with an opening angle eliminates the recirculation region after the coolant exits. This allows to accelerate the flow across the blade surface and increase the momentum deficit in the wake resulting in a reduction of the negative effect of the adverse pressure gradient. This is more apparent in configuration \#2 that the movement around the blade is energized due to the momentum of injected coolant and thus the flow remains attached to the upper surface. 

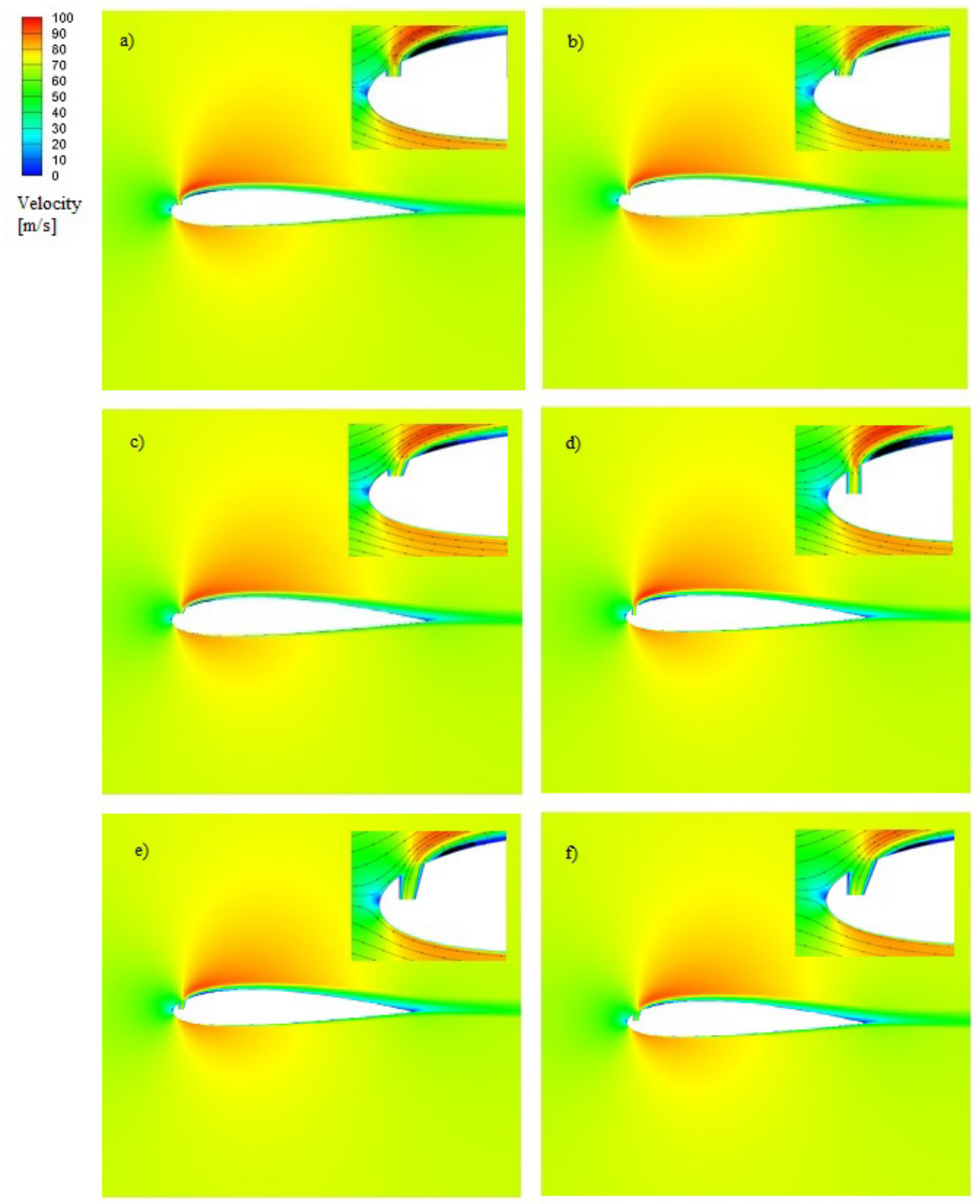

Figure 7 Velocity contours $(\mathrm{m} / \mathrm{s})$ and flow pattern around the blade; Configuration \#1 (a), Configuration \#2 (b), Configuration \#3 (c), Configuration \#4 (d), Configuration \#5 (e) and Configuration \#6 (f).

Figure 8 depicts a comparison of temperature distribution across the upper surface of the blade for various situations. It is clear that injection holes with opening angles do better than holes without opening angles. Configuration \#2 achieves the greatest temperature loss when more coolant is produced by the secondary flow and concentrates over the upper surface of the blade. It needs to be noted that shaping the injection hole with an opening angle improves film cooling on the blade. Increasing the height of the injection hole is undesirable to the cooling mechanism because it decreases coolant exit momentum and worsens attachment to the blade surface. These seem to reduce the amount of coolant entrained and brought to the leading edge by secondary flows. 


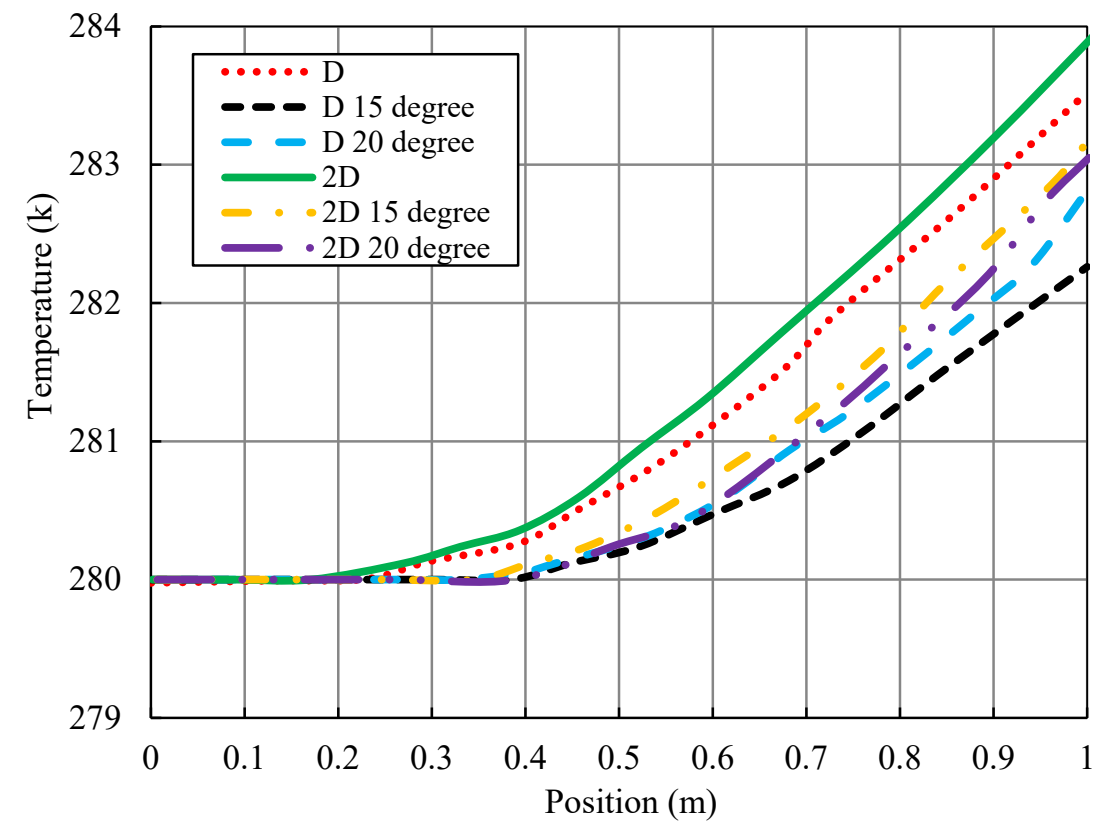

Figure 8 Temperature distribution over the blade for different cases.

Figure 9 indicates the comparison of cooling efficiency for different cases. In general, the film cooling mechanism is determined by interactions between the injected coolant streams and the secondary flows in the passage. In both cases, the highest film cooling effectiveness is found at the leading edge of the airfoil and gradually decreases downstream. It is obvious that injection holes with opening angles have a beneficial impact on cooling performance. Configuration \#2 achieves the highest amount of cooling efficiency. The coolant injected from configuration $\# 2$ in this case offers greater cooling coverage for the entire blade, increasing cooling effectiveness.

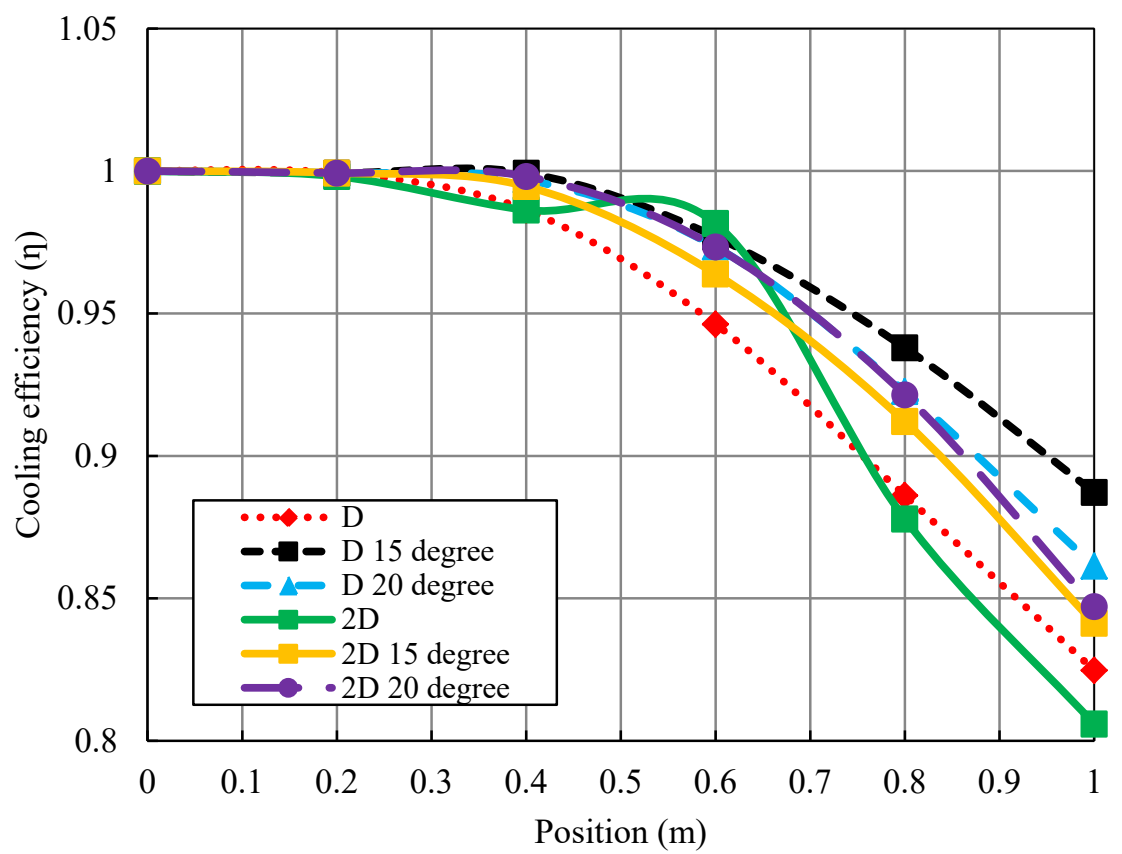

Figure 9 Comparison of cooling efficiency of injection holes for different cases. 


\section{Conclusions}

The main objective of the present research is to examine the film cooling mechanism on an asymmetric NACA 0012 gas turbine blade using injection holes. In addition, the effect of various geometries of injection holes on the effectiveness of film cooling has been numerically analyzed. Six different injection holes with and without opening angles are considered separately. By comparing the temperature distribution across the airfoil surface for both cases, it was determined that the injection hole has a greater effect on the cooling performance of the upper surface of the blade than other cases due to its lower height. The low opening angle $\left(15^{\circ}\right)$ has a greater influence on the cooling of the film than the other opening angles. Furthermore, the film cooling mechanism is often dependent on interactions between the injected coolant streams and secondary flows in the passage. The injection hole with an opening angle eliminates the recirculation region after the coolant exits. As a result, the accelerated flow of higher momentum spread uniformly around the blade, reducing the detrimental influence of the adverse pressure gradient.

\section{References}

[1] F Fangsu, C Wang and J Zhang. Large eddy simulation of film cooling on turbine vane. J. Therm. Sci. Technol. 2019; 14, JTST0014.

[2] S Mathew, S Ravelli and DG Bogard. Evaluation of CFD predictions using thermal field measurements on a simulated film cooled turbine blade leading edge. J. Turbomach. 2013; 135, 011021.

[3] F Lanzillotta, A Sciacchitano and AG Rao. Effect of film cooling on the aerodynamic performance of an airfoil. Int. J. Heat Fluid Flow 2017; 66, 108-20.

[4] G Narayanan, M Joshi, P Dutta and K Kalita. PSO-tuned support vector machine metamodels for assessment of turbulent flows in pipe bends. Eng. Comput. 2020; 37, 981-1001.

[5] N Ganesh, P Dutta, M Ramachandran, AK Bhoi and K Kalita. Robust metamodels for accurate quantitative estimation of turbulent flow in pipe bends. Eng. Comput. 2019; 36, 1041-58.

[6] R Abdelmaksoud, and T Wang. Simulation of air/mist cooling in a conjugate, 3-D gas turbine vane with internal passage and external film cooling. Int. J. Heat Mass Transf. 2020; 160, 120197.

[7] E Fatahian, N Kordani and H Fatahian. The Application of Computational Fluid Dynamics (CFD) method and several rheological models of blood flow: A review. Gazi Univ. J. Sci. 2018; 3, 121327.

[8] S Park, HS Sohn, S Shin, O Ueda, HK Moona and HH Cho. Film cooling characteristics on blade platform with a leakage flow through mid-passage gap. Int. J. Heat Mass Transf. 2021; 167, 120800.

[9] E Fatahian, H Salarian and H Fatahian. Numerical investigation of hazardous gas dispersion over obstacles and residential areas. Int. J. Eng. 2020; 33, 2087-94.

[10] E Fatahian, H Salarian and H Fatahian. A parametric study of the heat exchanger copper coils used in an indirect evaporative cooling system. SN Appl. Sci. 2020; 2, 112.

[11] H Fatahian, E Hosseini and E Fatahian. CFD simulation of a novel design of square cyclone with dual-inverse cone. Adv. Powder Technol. 2020; 31, 1748-58.

[12] $\mathrm{H}$ Wang, Z Tao and $\mathrm{H} \mathrm{Li}$. A tip region film cooling study of the fan-shaped hole using PSP. Int. J. Heat Mass Transf. 2020; 153, 119378.

[13] H Fatahian and E Fatahian. Improving efficiency of a square cyclone separator using a dipleg - a CFD-based analysis. Iran. J. Chem. Chem. Eng. 2020. https://doi.org/10.30492/ijcce.2020.127666. 4129.

[14] CL Liu, L Ye, F Zhang, R Huang and B Li. Film cooling performance evaluation of the furcate hole with cross-flow coolant injection: A comparative study. Int. J. Heat Mass Transf. 2021; 164, 120457.

[15] H Fatahian, H Salarian, J Khaleghinia and E Fatahian. Improving the efficiency of a savonius vertical axis wind turbine using an optimum parameters. Comput. Res. Prog. Appl. Sci. Eng. 2018; 4, 27-32.

[16] H Dai, J Zhang, Y Ren, N Liu and J Lin. Effect of cooling hole configurations on combustion and heat transfer in an aero-engine combustor. Appl. Therm. Eng. 2021; 182, 115664.

[17] Y Xia, P Sharkey, S Orsino, M Kuron, F Menter, I Verma and B Sen. Stress-blended eddy simulation/flamelet generated manifold simulation of film-cooled surface heat transfer and nearwall reaction. J. Turbomach. 2021; 143, 011008. 
[18] A Sari, H Fatahian and E Fatahian. Numerical investigation of heat transfer of flow over the cylinder with high conductivity fins. Comput. Res. Prog. Appl. Sci. Eng. 2017; 3, 85-95.

[19] P Chen, L Wang, X Li, J Ren and H Jiang. Effect of axial turbine non-axisymmetric endwall contouring on film cooling at different locations. Int. J. Heat Mass Transf. 2020; 147, 118995.

[20] SH Park, YJ Kang, HJ Seo, JS Kwak and YS Kang. Experimental optimization of a fan-shaped film cooling hole with 30 degrees-injection angle and 6-hole length-to-diameter ratio. Int. J. Heat Mass Transf. 2019; 144, 118652.

[21] DJ Jackson, KL Lee, PM Ligrani and PD Johnson. Transonic aerodynamic losses due to turbine airfoil, suction surface film cooling. J. Turbomach. 1999; 122, 317-26.

[22] BI Mamaev, R Saha and J Fridh. Aerodynamic investigation of turbine cooled vane block. Therm. Eng. 2015; 62, 97-102.

[23] W Colban, KA Thole and M Haendler. A comparison of cylindrical and fan-shaped film-cooling holes on a vane endwall at low and high freestream turbulence levels. J. Turbomach. 2008; 130, 031007.

[24] N Cao, X Li, Z Wu and X Luo. Effect of film hole geometry and blowing ratio on film cooling performance. Appl. Therm. Eng. 2020; 165, 114578.

[25] F Han, H Guo, XF Ding, DW Zhang and HW Li. Experimental investigation on the effects of hole pitch and blowing ratio on the leading edge region film cooling of a rotating twist turbine blade. Int. J. Heat Mass Transf. 2020; 150, 119380.

[26] J Zhou, X Wang, J Li and H Lu. Effects of diameter ratio and inclination angle on flow and heat transfer characteristics of sister holes film cooling. Int. Commun. Heat Mass Transf. 2020; 110, 104426.

[27] E Fatahian and H Fatahian. Simultaneous effect of suction and cavity for controlling flow separation on NACA 0012 airfoil - CFD approach. Gazi Univ. J. Sci. 2021; 34, 235-49.

[28] W Du, L Luo, S Wang and B Sunden. Film cooling in the trailing edge cutback with different land shapes and blowing ratios. Int. Commun. Heat Mass Transf. 2021; 125, 105311.

[29] H Fatahian, H Salarian, ME Nimvari and J Khaleghinia. Effect of Gurney flap on flow separation and aerodynamic performance of an airfoil under rain and icing conditions. Acta Mech. Sin. 2020; 36, 659-77.

[30] E Fatahian, H Fatahian, E Hosseini and G Ahmadi. A low-cost solution for the collection of fine particles in square cyclone: A numerical analysis. Powder Technol. 2021; 387, 454-65

[31] P Catalano and M Amato. An evaluation of RANS turbulence modelling for aerodynamic applications. Aerosp. Sci. Technol. 2003; 7, 493-509.

[32] E Fatahian, AL Nichkoohi and H Fatahian. Numerical study of the effect of suction at a compressible and high Reynolds number flow to control the flow separation over Naca 2415 airfoil. Prog. Comput. Fluid Dyn. 2019; 19, 170-9.

[33] E Fatahian, AL Nichkoohi, H Salarian and J Khaleghinia. Effects of the hinge position and suction on flow separation and aerodynamic performance of the NACA 0012 airfoil. J. Braz. Soc. Mech. Sci. Eng. 2020; 42, 86.

[34] K Lu, MT Schobeiri and JC Han. Numerical simulation of film cooling on rotating blade tips within a high-pressure turbine. In: Proceedings of the ASME Turbo Expo 2013: Turbine Technical Conference and Exposition, San Antonio, Texas, USA, 2013.

[35] SA Abdelfattah and MT Schobeiri. Experimental and numerical investigations of aerodynamic behavior of a three-stage HP-turbine at different operating conditions. In: Proceedings of the ASME Turbo Expo 2010: Power for Land, Sea, and Air, Glasgow, UK, 2010, p. 1619-32.

[36] FR Menter. Two-equation eddy-viscosity turbulence models for engineering applications. AIAA J. 1994; 32, 1598-605.

[37] W He, Q Deng, W Zhou, T Gao and Z Feng. Film cooling and aerodynamic performances of a turbine nozzle guide vane with trenched cooling holes. Appl. Therm. Eng. 2019; 150, 150-63.

[38] HK Versteeg and W Malalasekera. An introduction to computational fluid dynamics: The finite volume method. Pearson Education, London, 2007.

[39] N Gregory and CL O'reilly. Low-speed aerodynamic characteristics of NACA 0012 aerofoil section, including the effects of upper-surface roughness simulating hoar frost. HM Stationery Office, London, 1970. 